\title{
PELAKSANAAN TERTIB BERLALU LINTAS TERHADAP PEMAKAIAN HELM BAGI MAHASISWA PENGENDARA SEPEDA MOTOR DI DALAM AREA KAMPUS UNIVERSITAS LANCANG KUNING MENURUT UNDANG-UNDANG NOMOR 22 TAHUN 2009
}

\author{
${ }^{1}$ Rizana, ${ }^{2}$ Ade Pratiwi Susanty, ${ }^{3}$ Andrew Shandy Utama \\ Universitas Lancang Kuning \\ Email: ${ }^{3}$ andrew.fh.unilak@gmail.com
}

Info Artikel:

Diterima:25 September 2019 | Disetujui: 29 September 2019 | Dipublikasikan: 27 Desember 2019

\section{Abstrak}

Berdasarkan Pasal 106 Ayat (8) Undang-Undang Nomor 22 Tahun 2009 tentang Lalu Lintas dan Angkutan Jalan ditegaskan bahwa setiap orang yang mengemudikan sepeda motor dan penumpang sepeda motor wajib mengenakan helm yang memenuhi Standar Nasional Indonesia. Penelitian ini bertujuan untuk menjelaskan pelaksanaan tertib berlalu lintas terhadap pemakaian helm bagi mahasiswa pengendara sepeda motor di dalam area kampus Universitas Lancang Kuning menurut Undang-Undang Nomor 22 Tahun 2009 tentang Lalu Lintas dan Angkutan Jalan. Metode yang digunakan dalam penelitian ini adalah penelitian hukum sosiologis. Pelaksanaan tertib berlalu lintas terhadap pemakaian helm bagi mahasiswa pengendara sepeda motor di dalam area kampus Universitas Lancang Kuning belum terlaksana. Faktor yang menghambat adalah belum adanya peraturan internal di Universitas Lancang Kuning yang mewajibkan mahasiswa untuk memakai helm pada saat mengendarai sepeda motor di dalam area kampus. Meskipun dalam Undang-Undang Nomor 22 Tahun 2009 tentang Lalu Lintas dan Angkutan Jalan telah diatur mengenai sanksi bagi pengendara sepeda motor yang tidak memakai helm, tetapi penegakan hukum pelanggaran tertib berlalu lintas terhadap pemakaian helm bagi mahasiswa pengendara sepeda motor di dalam area kampus Universitas Lancang Kuning belum pernah diterapkan.

Kata kuci: Hukum, Lalu Lintas, Universitas Lancang Kuning

\section{IMPLEMENTATION OF TRAFFIC CONDITIONS FOR THE WEARING OF HELMET FOR STUDENT RIDERS MOTORCYCLES IN CAMPUS AREA LANCANG KUNING UNIVERSITY ACCORDING TO LAW NUMBER 22 OF 2009 \\ Abstract}

Based on Article 106 Paragraph (8) of Law Number 22 of 2009 concerning Traffic and Road Transportation, it is stated that every person driving a motorcycle and motorbike passengers are required to wear a helmet that meets the Indonesian National Standard. This research aims to explain the implementation of orderly traffic to the use of helmets for students who ride motorbikes in the campus area of Lancang Kuning University according to Law Number 22 of 2009 concerning Traffic and Road Transportation. The method used in this research is socio-legal research. The implementation of traffic order on the use of helmets for students riding motorbikes in the campus area of Lancang Kuning University hasn't yet been implemented. The inhibiting factor is the absence of an internal regulation at Lancang Kuning University which requires students to wear a helmet when riding a motorcycle in the campus area. Although Law Number 22 of 2009 concerning Traffic and Road Transportation has stipulated sanctions for motorcyclists who don't wear helmets, law enforcement of traffic order violations against the use of helmets for student motorcyclists within the campus area of Lancang Kuning University has never been implemented. 


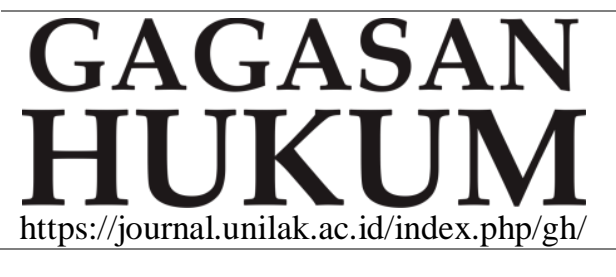

ISSN: $2714-8688$

Keywords: Law, Traffic, Lancang Kuning University 


\section{A. PENDAHULUAN}

Lalu lintas dan angkutan jalan mempunyai peran strategis dalam mendukung pembangunan dan integrasi nasional sebagai bagian dari upaya memajukan kesejahteraan umum sebagaimana diamanatkan oleh UndangUndang Dasar Negara Republik Indonesia Tahun 1945. Sebagai bagian dari sistem transportasi nasional, lalu lintas dan angkutan jalan harus dikembangkan potensi dan perannya untuk mewujudkan keamanan, kesejahteraan, ketertiban berlalu lintas dan angkutan jalan dalam rangka mendukung pembangunan ekonomi dan pengembangan ilmu pengetahuan dan teknologi, otonomi daerah, serta akuntabilitas penyelenggaraan negara.

Menurut Undang-Undang Republik Indonesia Nomor 22 Tahun 2009 tentang Lalu Lintas dan Angkutan Jalan dijelaskan bahwa lalu lintas adalah gerak kendaraan dan orang di ruang lalu lintas jalan, sedangkan angkutan adalah perpindahan orang dan/atau barang dari satu tempat ke tempat lain dengan menggunakan kendaraan di ruang lalu lintas jalan. Jadi, lalu lintas dan angkutan jalan didefinisikan sebagai satu kesatuan sistem yang terdiri atas lalu lintas, angkutan jalan, jaringan lalu lintas dan angkutan jalan, prasarana lalu lintas dan angkutan jalan, kendaraan, pengemudi, pengguna jalan, serta pengelolaannya (Rahardjo Adisasmita dan Sakti Adjie Adisasmita, 2015).

Dasar hukum yang mengatur mengenai penyelenggaraan lalu lintas dan angkutan jalan di Indonesia adalah UndangUndang Republik Indonesia Nomor 22 Tahun 2009 tentang Lalu Lintas dan Angkutan Jalan.

Jenis-jenis kendaraan menurut Undang-Undang Republik Indonesia Nomor 22 Tahun 2009 tentang Lalu Lintas dan Angkutan Jalan terbagi atas kendaraan bermotor dan kendaraan tidak bermotor. Kendaraan bermotor adalah setiap kendaraan yang digerakkan oleh peralatan mekanik berupa mesin, selain kendaraan yang berjalan di atas rel, sedangkan kendaraan tidak bermotor adalah setiap kendaraan yang digerakkan oleh tenaga manusia dan/atau hewan (Farouk Muhammad, 2016). Salah satu jenis kendaraan bermotor yang menjadi objek dalam penelitian ini adalah sepeda motor.

Pada Pasal 57 Undang-Undang Republik Indonesia Nomor 22 Tahun 2009 tentang Lalu Lintas dan Angkutan Jalan disebutkan bahwa setiap kendaraan bermotor yang dioperasikan di jalan wajib dilengkapi dengan perlengkapan kendaraan bermotor, bagi sepeda motor berupa helm standar nasional Indonesia (SNI). Berdasarkan observasi prapenelitian yang dilakukan di Universitas Lancang Kuning, peneliti melihat langsung bahwa banyak 
mahasiswa Universitas Lancang Kuning yang tidak memakai helm pada saat mengendarai sepeda motor di dalam area kampus. Padahal memakai helm, terutama helm SNI, merupakan amanat dari UndangUndang Republik Indonesia Nomor 22 Tahun 2009 tentang Lalu Lintas dan Angkutan Jalan karena dapat menjaga keselamatan pengendara pada bagian kepala apabila terjadi kecelakaan lalu lintas.

Dari latar belakang masalah yang telah dijelaskan di atas, maka tujuan dari penelitian ini yaitu sebagai berikut:

1. Untuk menjelaskan pelaksanaan tertib berlalu lintas terhadap pemakaian helm bagi mahasiswa pengendara sepeda motor di dalam area kampus Universitas Lancang Kuning menurut Undang-Undang Nomor 22 Tahun 2009 tentang Lalu Lintas dan Angkutan Jalan.

2. Untuk menjelaskan faktor-faktor yang menghambat dalam pelaksanaan tertib berlalu lintas terhadap pemakaian helm bagi mahasiswa pengendara sepeda motor di dalam area kampus Universitas Lancang Kuning menurut Undang-Undang Nomor 22 Tahun 2009 tentang Lalu Lintas dan Angkutan Jalan.

3. Untuk menjelaskan penegakan hukum pelanggaran tertib berlalu lintas terhadap pemakaian helm bagi mahasiswa pengendara sepeda motor di dalam area kampus Universitas Lancang Kuning menurut Undang-Undang Nomor 22 Tahun 2009 tentang Lalu Lintas dan Angkutan Jalan.

\section{B. METODE PENELITIAN}

Penelitian hukum adalah suatu kegiatan ilmiah yang didasarkan pada metode, sistematika, dan pemikiran tertentu yang bertujuan untuk mempelajari satu atau beberapa gejala hukum tertentu dengan jalan menganalisanya (Soerjono Soekanto, 2007). Metode yang digunakan dalam penelitian ini adalah penelitian hukum sosiologis. Penelitian hukum sosiologis adalah suatu penelitian yang dilakukan dengan cara menjelaskan pelaksanaan peraturan perundang-undangan terhadap permasalahan yang ada di masyarakat (Zainuddin Ali, 2013). Sumber data yang digunakan dalam penelitian ini adalah data primer dan data sekunder. Data primer yaitu data yang diperoleh langsung dari hasil observasi, wawancara, dan kuisioner di lokasi penelitian; sedangkan data sekunder yaitu data yang diperoleh dari jurnal-jurnal ilmiah, literatur hukum, dan peraturan perundang-undangan. Teknik pengumpulan data yang digunakan dalam penelitian ini adalah observasi, wawancara, dan studi kepustakaan. Teknik analisis data yang digunakan dalam penelitian ini adalah analisis kualitatif. 


\section{HASIL DAN PEMBAHASAN}

Dasar hukum yang mengatur mengenai penyelenggaraan lalu lintas dan angkutan jalan di Indonesia adalah UndangUndang Republik Indonesia Nomor 22 Tahun 2009 tentang Lalu Lintas dan Angkutan Jalan (Farouk Muhammad, 2012)

Menurut Undang-Undang Republik Indonesia Nomor 22 Tahun 2009 tentang Lalu Lintas dan Angkutan Jalan dijelaskan bahwa lalu lintas adalah gerak kendaraan dan orang di ruang lalu lintas jalan, sedangkan angkutan adalah perpindahan orang dan/atau barang dari satu tempat ke tempat lain dengan menggunakan kendaraan di ruang lalu lintas jalan. Jadi, lalu lintas dan angkutan jalan didefinisikan sebagai satu kesatuan sistem yang terdiri atas lalu lintas, angkutan jalan, jaringan lalu lintas dan angkutan jalan, prasarana lalu lintas dan angkutan jalan, kendaraan, pengemudi, pengguna jalan, serta pengelolaannya (Rahardjo Adisasmita dan Sakti Adjie Adisasmita, 2015).

Asas-asas dalam penyelenggaraan lalu lintas dan angkutan jalan di Indonesia sebagaimana yang diatur dalam UndangUndang Republik Indonesia Nomor 22 Tahun 2009 tentang Lalu Lintas dan Angkutan Jalan adalah sebagai berikut: Asas Transparan, yaitu keterbukaan dalam penyelenggaraan lalu lintas dan angkutan jalan kepada masyarakat luas dalam memperoleh informasi yang benar, jelas, dan jujur sehingga masyarakat mempunyai kesempatan berpartisipasi bagi pengembangan lalu lintas dan angkutan jalan; asas Akuntabel, yaitu penyelenggaraan lalu lintas dan angkutan jalan yang dapat dipertanggungjawabkan; asas Berkelanjutan, yaitu penjaminan kualitas fungsi lingkungan melalui pengaturan persyaratan teknis laik kendaraan dan rencana umum pembangunan serta pengembangan jaringan lalu lintas dan angkutan jalan; asas Partisipatif, yaitu pengaturan peranserta masyarakat dalam proses penyusunan kebijakan, pengawasan terhadap pelaksanaan kebijakan, penanganan kecelakaan, dan pelaporan atas peristiwa yang terkait dengan lalu lintas dan angkutan jalan; asas Bermanfaat, yaitu semua kegiatan penyelenggaraan lalu lintas dan angkutan jalan yang dapat memberikan nilai tambah sebesar-besarnya dalam rangka mewujudkan kesejahteraan masyarakat; asas Efisien dan Efektif, yaitu pelayanan dalam penyelenggaraan lalu lintas dan angkutan jalan yang dilakukan oleh setiap pembina pada jenjang pemerintahan secara berdaya guna dan berhasil guna; asas Seimbang, yaitu penyelenggaraan lalu lintas dan angkutan jalan yang harus dilaksanakan atas dasar keseimbangan antara sarana dan prasarana serta pemenuhan hak dan kewajiban pengguna jasa dan penyelenggara; asas 
Terpadu, yaitu penyelenggaraan pelayanan lalu lintas dan angkutan jalan yang dilakukan dengan mengutamakan keserasian dan kesalingbergantungan kewenangan dan tanggung jawab antarinstansi pembina; asas mandiri, yaitu upaya penyelenggaraan lalu lintas dan angkutan jalan melalui pengembangan dan pemberdayaan sumber daya nasional.

Penyelenggaraan lalu lintas dan angkutan jalan di Indonesia sebagaimana yang diatur dalam Undang-Undang Republik Indonesia Nomor 22 Tahun 2009 tentang Lalu Lintas dan Angkutan Jalan bertujuan untuk: terwujudnya pelayanan lalu lintas dan angkutan jalan yang aman, selamat, tertib, lancar, dan terpadu dengan moda angkutan lain untuk mendorong perekonomian nasional, memajukan kesejahteraan umum, memperkokoh persatuan dan kesatuan bangsa, serta mampu menjunjung tinggi martabat bangsa; terwujudnya etika berlalu lintas dan budaya bangsa; terwujudnya penegakan hukum dan kepastian hukum bagi masyarakat.

Ruang lingkup pengaturan lalu lintas dan angkutan jalan dalam Undang-Undang Republik Indonesia Nomor 22 Tahun 2009 tentang Lalu Lintas dan Angkutan Jalan adalah untuk membina dan menyelenggarakan lalu lintas dan angkutan jalan yang aman, selamat, tertib, dan lancar melalui: kegiatan gerak pindah kendaraan, orang, dan/atau barang di jalan; kegiatan yang menggunakan sarana, prasarana, dan fasilitas pendukung lalu lintas dan angkutan jalan; kegiatan yang berkaitan dengan registrasi dan identifikasi kendaraan bermotor dan pengemudi, pendidikan berlalu lintas, manajemen dan rekayasa lalu lintas, serta penegakan hukum lalu lintas dan angkutan jalan.

Berdasarkan Pasal 57 UndangUndang Republik Indonesia Nomor 22 Tahun 2009 tentang Lalu Lintas dan Angkutan Jalan diatur bahwa setiap kendaraan bermotor yang dioperasikan di jalan wajib dilengkapi dengan perlengkapan kendaraan bermotor, bagi sepeda motor berupa helm Standar Nasional Indonesia (SNI). Sejalan dengan itu, berdasarkan Pasal 106 Ayat (8) Undang-Undang Republik Indonesia Nomor 22 Tahun 2009 tentang Lalu Lintas dan Angkutan Jalan ditegaskan bahwa setiap orang yang mengemudikan sepeda motor dan penumpang sepeda motor wajib mengenakan helm yang memenuhi Standar Nasional Indonesia.

Pelaksanaan tertib berlalu lintas terhadap pemakaian helm bagi mahasiswa pengendara sepeda motor di dalam area kampus Universitas Lancang Kuning belum terlaksana. Dari hasil observasi penelitian yang dilakukan pada hari Kamis tanggal 10 September 2020 di dalam area kampus Universitas Lancang Kuning, peneliti melihat langsung bahwa terdapat beberapa 
orang mahasiswa Universitas Lancang Kuning yang tidak memakai helm pada saat mengendarai sepeda motor di dalam area kampus. Padahal memakai helm, terutama helm Standar Nasional Indonesia, merupakan kewajiban pengendara sepeda motor dalam rangka menjaga keselamatannya, terutama pada bagian kepala, apabila terjadi kecelakaan lalu lintas.

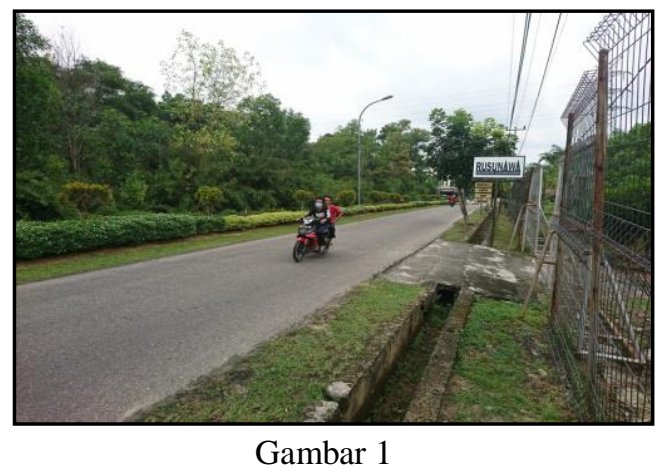

Foto Mahasiswa yang Tidak Memakai Helm pada Saat Berkendara di dalam Area Kampus hari Kamis tanggal 10 September 2020

Faktor yang menghambat dalam pelaksanaan tertib berlalu lintas terhadap pemakaian helm bagi mahasiswa pengendara sepeda motor di dalam area kampus Universitas Lancang Kuning adalah belum adanya peraturan internal di Universitas Lancang Kuning yang mewajibkan mahasiswa untuk memakai helm pada saat mengendarai sepeda motor di dalam area kampus. Dari hasil wawancara penelitian yang dilakukan dengan salah seorang mahasiswa Universitas Lancang Kuning yang bernama Vini Amelia dan Selvin Delpian pada hari
Senin tanggal 14 September 2020 diketahui bahwa selama ini tidak ada pemeriksaan hingga larangan dari pihak kampus kepada mahasiswa yang tidak memakai helm pada saat mengendarai sepeda motor di dalam area kampus.

Dalam artikel yang berjudul "Peranan Polisi Lalu Lintas dalam Mengawasi Penggunaan Helm oleh Pengendara Sepeda Motor di Wilayah Hukum Kepolisian Resor Kota Pekanbaru”, Mayzatul Laili menjelaskan bahwa pengawasan terhadap penggunaan helm oleh pengendara sepeda motor yang dilakukan oleh Satuan Lalu Lintas Kepolisian Resor Kota Pekanbaru belum terlaksana dengan baik karena masih banyak ditemukan pengendara sepeda motor yang tidak menggunakan helm pada saat berkendara di jalan raya (Mayzatul Laili, 2016). Sejalan dengan itu, dalam artikel yang berjudul "Pelaksanaan Tilang Kendaraan Bermotor di Kota Pekanbaru”, Yansen Yohanes Siahaan menjelaskan bahwa penegakan hukum terhadap pelanggaran lalu lintas di Kota Pekanbaru dilaksanakan oleh Satuan Lalu Lintas Kepolisian Resor Kota Pekanbaru. Pelanggaran lalu lintas yang ditilang pada tahun 2015 berjumlah 38.803 kasus, naik dari tahun sebelumnya yang berjumlah 28.206 kasus. Pelanggaran lalu lintas di Kota Pekanbaru sebagian besar dilakukan 
oleh pengendara sepeda motor (Yansen Yohanes Siahaan, 2017).

Berdasarkan Pasal 291 UndangUndang Republik Indonesia Nomor 22 Tahun 2009 tentang Lalu Lintas dan Angkutan Jalan ditegaskan bahwa setiap orang yang mengemudikan sepeda motor tidak mengenakan helm Standar Nasional Indonesia dipidana dengan pidana kurungan paling lama 1 (satu) bulan atau denda paling banyak Rp250.000,- (dua ratus lima puluh ribu rupiah). Meskipun dalam Undang-Undang Republik Indonesia Nomor 22 Tahun 2009 tentang Lalu Lintas dan Angkutan Jalan telah diatur mengenai sanksi bagi pengendara sepeda motor yang tidak memakai helm, tetapi menurut Wakil Rektor III Universitas Lancang Kuning, Dr. Bagio Kadaryanto, S.H., M.H., penegakan hukum pelanggaran tertib berlalu lintas terhadap pemakaian helm bagi mahasiswa pengendara sepeda motor di dalam area kampus Universitas Lancang Kuning belum pernah diterapkan. Hal ini karena penegakan hukum terhadap pengendara sepeda motor yang tidak memakai helm Standar Nasional Indonesia merupakan kewenangan dari pihak kepolisian, yaitu Satuan Lalu Lintas (Satlantas) Kepolisian Resor Kota (Polresta) Pekanbaru.

Universitas Lancang Kuning sebaiknya membuat peraturan mengenai kewajiban memakai helm bagi mahasiswa yang mengendarai sepeda motor di dalam area kampus. Selain merupakan wujud kepatuhan terhadap Undang-Undang Republik Indonesia Nomor 22 Tahun 2009 tentang Lalu Lintas dan Angkutan Jalan, kebijakan tersebut juga bermanfaat bagi mahasiswa rangka menjaga keselamatannya, terutama pada bagian kepala, apabila terjadi kecelakaan lalu lintas.

Universitas Lancang Kuning sebaiknya bekerja sama dengan pihak Satuan Lalu Lintas (Satlantas) Kepolisian Resor Kota (Polresta) Pekanbaru dalam menjaga ketertiban lalu lintas di dalam area kampus agar Universitas Lancang Kuning menjadi kampus yang tertib dalam berlalu lintas sehingga siap menjadi universitas yang unggul di tingkat nasional pada tahun 2030.

Dalam artikel yang berjudul "Penyuluhan Hukum Keselamatan Lalu Lintas sebagai Strategi Mewujudkan Budaya Patuh Hukum Lalu Lintas", Raja Desril menjelaskan bahwa tata tertib berlalu lintas bertujuan untuk mewujudkan dan memelihara ketertiban dan kelancaran serta keselamatan dalam berlalu lintas. Pelanggaran lalu lintas terjadi karena ada ketidaksesuaian antara peraturan dengan pelaksanaannya. Pelanggaran lalu lintas di Kota Pekanbaru kebanyakan dilakukan oleh pelajar dan bentuk pelanggarannya berupa tidak memakai helm pada saat mengendarai sepeda motor. Oleh karena itu, penting 
diadakan penyuluhan hukum mengenai Kepatuhan Berlalu Lintas kepada pelajar di sekolah-sekolah yang ada di Kota Pekanbaru (Raja Desril, 2018).

Negara bertanggung jawab atas lalu lintas dan angkutan jalan dan pembinaannya dilaksanakan oleh pemerintah. Pembina lalu lintas dan angkutan jalan bertangggung jawab membangun dan mewujudkan budaya keamanan dan keselamatan lalu lintas dan angkutan jalan. Upaya membangun dan mewujudkan budaya keamanan dan keselamatan lalu lintas dan angkutan jalan dilakukan melalui (Rahardjo Adisasmita dan Sakti Adjie Adisasmita, 2015): pelaksanaan pendidikan berlalu lintas sejak usia dini; sosialisasi dan internalisasi tata cara dan etika berlalu lintas serta program keamanan dan keselamatan lalu lintas dan angkutan jalan; pemberian penghargaan terhadap tindakan keamanan dan keselamatan lalu lintas dan angkutan jalan; penciptaan lingkungan ruang lalu lintas yang mendorong pengguna jalan berperilaku tertib; penegakan hukum secara konsisten dan berkelanjutan

\section{DAFTAR PUSTAKA}

Andrew Shandy Utama. 2019. Kepercayaan Masyarakat terhadap Penegakan Hukum di Indonesia. Jurnal Ensiklopedia Social Review, Volume 1, Nomor 3, Hal. 306-313.

Eko Ardiansyah Pandiangan, Erdianto, dan Ledy Diana. 2016. Penerapan Prinsip

\section{PENUTUP}

Pelaksanaan tertib berlalu lintas terhadap pemakaian helm bagi mahasiswa pengendara sepeda motor di dalam area kampus Universitas Lancang Kuning belum terlaksana. Faktor yang menghambat adalah belum adanya peraturan internal di Universitas Lancang Kuning yang mewajibkan mahasiswa untuk memakai helm pada saat mengendarai sepeda motor di dalam area kampus. Meskipun dalam Undang-Undang Nomor 22 Tahun 2009 tentang Lalu Lintas dan Angkutan Jalan telah diatur mengenai sanksi bagi pengendara sepeda motor yang tidak memakai helm, tetapi penegakan hukum pelanggaran tertib berlalu lintas terhadap pemakaian helm bagi mahasiswa pengendara sepeda motor di dalam area kampus Universitas Lancang Kuning belum pernah diterapkan.

Strict

Liability

dalam

Pertanggungjawaban Korporasi yang Dianggap Bertanggung Jawab atas Kebakaran Hutan di Provinsi Riau. Jurnal Online Mahasiswa (JOM) Fakultas Hukum Universitas Riau, Volume III, Nomor 2. 
Geovani Meiwanda. 2016. Kapabilitas Pemerintah Daerah Provinsi Riau; Hambatan dan Tantangan Pengendalian Kebakaran Hutan dan Lahan. Jurnal Sosial Politik, Volume 19, Nomor 3.

Hendra Eriant Dikser, Erdianto, dan Widia Edorita. 2017. Analisis Yuridis terhadap Pengecualian Pembakaran Lahan dan Hutan Berdasarkan Pasal 69 Ayat (2) Undang-Undang Nomor 32 Tahun 2009 tentang Perlindungan dan Pengelolaan Lingkungan Hidup. Jurnal Online Mahasiswa (JOM) Fakultas Hukum Universitas Riau, Volume IV, Nomor 2.

Salim H.S. Dasar-dasar Hukum Kehutanan. Jakarta: Sinar Grafika, 2013.

Soerjono Soekanto. Pengantar Penelitian Hukum. Jakarta: UI Press, 2007.
Soerjono Seokanto. Faktor-faktor yang Mempengaruhi Penegakan Hukum. Jakarta: Rajawali Pers, 2013.

Supriadi. Hukum Kehutanan dan Hukum Perkebunan di Indonesia. Jakarta: Sinar Grafika, 2010.

Wartiningsih. Pidana Kehutanan; Keterlibatan dan Pertanggungjawaban Penyelenggara Kebijakan Kehutanan. Malang: Setara Press, 2014.

Zainuddin Ali. Metode Penelitian Hukum. Jakarta: Sinar Grafika, 2013. 